\title{
Alcohol and older people from a public health perspective
}

\author{
Peter Anderson $^{(\text {a) }}$, Emanuele Scafato ${ }^{(\text {b) }}$ and Lucia Galluzzo ${ }^{(b)}$ \\ for the VINTAGE project Working Group* \\ (a) Faculty of Health, Medicine and Life Sciences, Maastricht University, Maastricht, The Netherlands \\ (b) WHO Collaborating Centre for Research \& Health Promotion on Alcohol and Alcohol-Related \\ Health Problems, Osservatorio Nazionale Alcol, Centro Nazionale di Epidemiologia, Sorveglianza e \\ Promozione della Salute, Istituto Superiore di Sanità, Rome, Italy \\ *see Appendix
}

\begin{abstract}
Objectives and methods. As part of the European project VINTAGE, a systematic review of scientific literature was undertaken to document the evidence base on the impact of alcohol on the health and well-being of older people, and on effective policies and preventive approaches to face the problem in this steadily increasing segment of the population. Results. 369 references were identified, from which 78 papers were selected. Conclusions. The review confirms the paucity of data on this topic and the need for more specific research. Although there is scarce evidence, the elderly seems to respond equally well to alcohol policy, screening instruments and brief interventions as do younger adults. According to a lifecycle approach, a future focus on the middle aged is also recommended.
\end{abstract}

Key words: aged, alcohol drinking, public health, Europe, review.

Riassunto (Alcol e anziani in una prospettiva di salute pubblica). Obiettivi e Metodi. Nell'ambito del progetto europeo VINTAGE, è stata condotta una revisione sistematica della letteratura scientifica, al fine di fornire la base di evidenza sull'impatto del consumo di alcol sulla salute e il benessere degli anziani, e su misure e interventi di prevenzione efficaci nel fronteggiare il problema in questo segmento della popolazione in costante aumento. Risultati. Dai 369 riferimenti bibliografici identificati, sono stati selezionati 78 articoli. Conclusioni. La revisione conferma la carenza di dati sull'argomento e la necessità di ricerche mirate. Nonostante la scarsità di evidenze, sembra che gli anziani rispondano altrettanto bene degli adulti alle politiche sull'alcol, agli strumenti di screening e all'intervento breve. In un'ottica che investe l'intero arco della vita, si raccomanda di focalizzare gli interventi futuri anche sugli adulti.

Parole chiave: anziani, assunzione di alcolici, salute pubblica, Europa, rassegna.

\section{INTRODUCTION}

Most Europeans drink alcohol, which is associated with more than sixty medical disorders and conditions [1], and which is estimated to be responsible for some ten per cent of the total disease and injury burden in Europe [2]. Alcohol use is linked to serious social problems, including violence, crime and work absenteeism.

As the 2009 Council of the European Union Conclusions on Alcohol and Health noted [3], there are a number of reasons to consider reviewing the impact of alcohol on older people in the European Union (EU) and what can be done about it [4, 5].

First, much less is known about the health, social and economic impacts of alcohol use in older people compared to younger adults.

Second, there are relevant biological changes associated with ageing. Research suggests that older people might be more sensitive to alcohol's negative health effects compared to younger adults, which could mean that more harm results from equivalent amounts of consumption by older people. One reason for this heightened sensitivity is the higher blood alcohol concentration (BAC) achieved by older compared to younger people after consuming an equal amount of alcohol. Ageing also interferes with the body's ability to adapt to the presence of alcohol (i.e. tolerance) and, through this decreased ability to develop tolerance, older people may continue to exhibit certain effects of alcohol (e.g. coordination problems) at lower doses than younger people whose tolerance increases with increasing consumption [6]. Brain research also suggests that ageing may render a person more susceptible to alcohol's effects. For example, it has been reported that older people with a history of chronic, heavy alcohol use exhibit more 
brain tissue loss than younger people, often despite similar lifetime alcohol consumption [7].

Third, there are the demographic changes in the EU. The older population is the fastest growing segment of the EU. Due largely to the ageing baby boomer generation of the post second world war years, the number of people aged 65 years and older is estimated to increase from 86.8 million in 2010 to 122.5 million in 2030. The number of people over 80 years of age is estimated to increase from 23.3 million in 2010 to 36 million in 2030 [8]. Average life expectancy has risen by five years for women (to 81 years) and four years for men (to 76 years) since 1960, and will continue to rise in the coming decades [9]. These changes will have an enormous impact on the European society. The ageing baby boomers are high alcohol consumers and will bring with them a significant cultural shift favourable to alcohol and drug use. Further, an older population typically increases the overall health burden and poses many challenges for public health policymakers. Demographic shifts have been paralleled by improvements in average disposable incomes and the buying power of many older Europeans, which generally lead to increases in alcohol consumption; although it is likely that future cohorts of older people will experience less prosperity. The ageing of the European population means that the absolute number of older EU citizens with alcohol-use disorders is likely to rise and the impact of these changes must be considered.

Despite the extent of alcohol use among older people and this demographic shift, there are surprisingly few recent systematic reviews that document the full extent of such harm, or that provide the evidence base for cost effective policies and programmes to reduce it, investing in the health and well-being of older persons. Following these considerations, the objective of the present work, which is part of the European project VINTAGE - Good Health into Older Age, is that of reducing this knowledge gap, by providing the evidence base of the impact of alcohol drinking on the health and well-being of older people and on prevention of harmful alcohol use among them.

\section{MATERIALS AND METHODS}

The present work is part of the VINTAGE - Good Health into Older Age that has been previously described in detail in this monographic issue. In brief, the main objectives of the VINTAGE project were:

- to review the evidence on the impact of alcohol on the health and well-being of older people and on prevention of harmful alcohol use among them;

- to collect European examples of best practices, laws and infrastructures to prevent alcohol harmful use among older people;

- to disseminate main findings to those responsible for alcohol policy and programme development, or working in the fields of health and welfare of the elderly;

in order to build the capacity and knowledge and to encourage evidence- and experience-based decisions for the improvement of older people health and well-being, including the transition from work to retirement, at European, national and local level.

Formal literature searches of the scientific literature were undertaken in PubMed, MEDLINE, the Cochrane Library and Google scholar using the search terms adapted from Table 1. Searches were restricted to the English language and since the year 2000. Key reviews of the impact of alcohol policies in reducing the harm done by alcohol were screened for information on older people $[10,11,2]$. Three hundred and sixty-nine titles and abstracts were indentified in the search, from which 78 papers were retrieved. Selected papers were those that were systematic reviews or original papers not included in systematic reviews. Papers already included in systematic reviews and clinically or practice oriented papers were excluded.

Selected papers were analysed in the attempt to answer a number of questions to do with alcohol and older people, including the pharmacokinetics of alcohol, and what we know about the use of alcohol and trends in consumption and alcoholrelated harm amongst older people. This systematic review of literature considers the relationships

Table 1 | Search terms used for VINTAGE formal literature searches

\section{No. Search history}

1. "AGED 80 AND OVER"/ OR AGED/

2. "middle aged"

3. (retired or retirement)

4. (elderly or gertiatr\$ or senile\$ or older or older adult or older person or old age or later life). $\mathrm{Ti}$, ab.

5. (injury $\mathrm{OR}$ death $\mathrm{OR}$ mortality $\mathrm{OR}$ fatality $\mathrm{OR}$ trauma $\mathrm{OR}$ fall $\mathrm{OR}$ violent $O R$ fracture $O R$ crash $O R$ accident $O R$ suicide $O R$ disorder $\mathrm{OR}$ assault $\mathrm{OR}$ murder $\mathrm{OR}$ homicide $\mathrm{OR}$ motor $\mathrm{OR}$ driv\$). $\mathrm{Ti}$, ab.

6. (cancer or liver or cirrhosis or cardiovascular or cerebrovascular or stroke or coronary or heart or ischemic or ischaemic or atherosclerosis or depress\$ or cognit\$ or brain or dementia or alzheimers or bone or diabetes or hospital\$ or drug or medication or comorbid or dependence or disorder). Ti, ab.

7. (educat\$ or train\$ or promot\$ or interven\$ or program\$ or administer\$ or campaign\$ or evaluat\$ or assess\$ or control\$ or compar\$ or prevent\$ or safe\$ or strateg\$ or scheme\$ or incentive $\$$ or trial\$ or policy or policies or reduc $\$$ or approach\$ or enforce $\$$ or guideline). $\mathrm{Ti}, \mathrm{ab}$.

8. (drink $\$$ or consum $\$$ or heavy or binge or episodic or risk $\$$ or safe or pattern). $\mathrm{Ti}, \mathrm{ab}$

9. alcohol\$. Ti, ab.

10. or $/ 1-4$

11. or $/ 5-8$

12. and $/ 9-11$ 
between alcohol and well-being and health in older people. It then considers how alcohol policy might impact on older people's use of alcohol, and the evidence for the effect of screening and brief intervention programmes amongst older people. The approach and focus is public health, rather than the treatment of those with alcohol use disorders. When considering alcohol policy and older people, the review notes the importance of the ageing middle aged population, a cohort with high levels of alcohol consumption and alcohol-related harm, and which will be the future older population.

The results of the literature searches were summarized in the VINTAGE report on alcohol and older people, which is freely accessible online from the project official website [12].

\section{RESULTS \\ Alcohol pharmacokinetics}

Ethanol $\left(\mathrm{C}_{2} \mathrm{H}_{5} \mathrm{OH}\right)$ is a physiologically nonessential, energy-yielding $(29 \mathrm{~kJ} / \mathrm{g}$ or $7 \mathrm{kcal} / \mathrm{g})$ molecule produced by alcoholic fermentation from plants with high carbohydrate content (e.g. barley, wheat, corn, and grapes) [13]. Ethanol does not need to be digested and is absorbed from the gut directly. Already in the stomach, some of the ethanol is metabolized by gastric alcohol dehydrogenase (ADH). In older adults, gastric ADH activity is significantly reduced, potentially increasing the amount of ethanol available to be absorbed with age. Alcohol that is not metabolized in the stomach diffuses across the stomach and the first part of the intestine to enter the body, where it first passes through the liver.

The liver is the primary site of ethanol metabolism. Hepatic ADH is the rate-limiting enzyme that oxidizes alcohol to acetaldehyde. In older adults, liver $\mathrm{ADH}$ activity is also significantly reduced, increasing the amount of ethanol that reaches the blood stream with age.

Maximal BACs are reached approximately 45 to 75 minutes after an oral dose of alcohol in 20- to 60year olds [13]. Body composition is altered by aging and this influences BAC. Whereas young adult body mass is approximately $70 \%$ water, by age 65 years, body fat doubles in men and increases by $50 \%$ in women resulting in reduced total body water. This means that, compared with younger people, BACs are likely to reach a higher level at any given alcohol intake.

A potential consequence of increased alcohol consumption is oxidative stress, which is implicated as a risk factor for many lifestyle-related diseases, including cancer, cardiovascular disease, and diabetes mellitus [13]. Oxidative stress occurs when there is an imbalance between anti-oxidant systems and the production of reactive oxygen species. These reactive molecules are generated in response to the metabolism of ethanol by the microsomal ethanol oxidizing system, and may have a role in the development of alcoholic liver disease. Unhealthy nutrient status may occur when food is displaced by increased alcohol intake. Potential displaced nutrients are B vitamins, notably thiamine and pyridoxine.

A reduction in n-3 polyunsaturated fatty acid intake, which is protective against coronary heart disease, has been associated with three or more daily drinks of alcohol [14]. As well, the requirements for some micronutrients (e.g. niacin and riboflavin) may be increased due to alcohol metabolism.

One consequence of the pharmacokinetic processes that might lead to older people being more susceptible to the impact of consumed alcohol than younger people has been to suggest lower guidelines for lower risk drinking amongst older people compared with younger people, as is the case in Italy.

Further epidemiological studies to compare whether or not older people show an increased risk of harm per gram of alcohol, when compared with younger people would confirm the importance of this approach.

\section{Alcohol consumption in older people}

The GENACIS project reported in 35 countries worldwide, including eleven EU countries, that the prevalence of current drinking did not decline with increasing age amongst the majority of studies undertaken during the early 2000 s, with still very high proportions of drinkers amongst those aged 50-65 years [15]; high frequency drinking ( $\geq 5$ days/week) tended to increase with age and high volume drinking (>23 g/day) did not regularly decrease with age, and often increased with age certainly for men and most likely for women. Although episodic heavy drinking ( $\geq 60 \mathrm{~g}$ in a day in preceding 12 months) tended to decrease with age, still a very high proportion of those aged 50-65 years engaged in this activity. Whether or not the cohorts of heavier drinking middle age people continue to drink more heavily as they age remains to be seen.

A comprehensive review of alcohol consumption amongst elderly EU citizens published in 2009 and reviewing data from the Czech Republic, Germany, Finland, Italy, Latvia, Poland, Spain, Sweden and the United Kingdom suggested that there were some increases in alcohol consumption in older people in some European countries, but it was difficult to say that this was a large, consistent or worrying trend in terms of drinking rates, volume of consumption or risky patterns of drinking, all of which were substantially lower than in the middle aged population [16]. There was no evidence of disproportionate changes in the drinking of older people compared with that of younger people. That is, any trends in the volumes and patterns of drinking amongst older people mirrored those of the population as a whole.

On the other hand, there is some evidence of cohort effects. In Italy, for example, whilst the prevalence of alcohol use during the previous twelve months declined with age in 2007, this was not the case for wine. This could be a cohort effect, with the older generations continuing the pattern of wine consumption during meals. 
There is some evidence in Spain that between 1987 and 2006, self-reported alcohol use during the prior two weeks increased more quickly amongst those aged 65 years and older than the general population. But, this could also be a cohort effect, with the previous higher prevalence of alcohol use (drinking with meals) amongst the middle aged persisting into older age, with such patterns diminishing amongst younger drinkers.

Despite the strong body of research on alcohol consumption patterns in young and middle-aged people, very little work on older people (especially those aged 80 years or more) has been undertaken. As a result, knowledge about the characteristics of drinkers and heavy drinkers in this age group remains limited.

One example of an exception to this is the UK based Medical Research Council (MRC) Trial of the Assessment and Management of Older People in the community, a cluster randomised trial investigating different approaches to multidimensional screening for people 75 years of age and over with randomisation by practice [17]. Among the 14962 responders, as would be expected, a higher proportion of women than men were never drinkers, whereas the heavier drinkers tended to be male. Overall, about $10 \%$ of the cohort drank between 7 and 13 drinks in the past week, and very few people drank more than this. Only $5 \%$ of men and $2.5 \%$ of women exceeded the Royal Colleges of Physicians, Psychiatrists and General Practitioners recommended weekly drinking limits (168 $\mathrm{g}$ for men and $112 \mathrm{~g}$ for women).

Over half of the drinkers drank mostly wine, with $30 \%$ drinking mostly beer and just over $12 \%$ drinking mostly spirits. In relative terms, women tended to drink more wine and spirits, and men favoured beer. In both men and women, the never drinkers were older, whereas the heavier drinkers tended to be younger. The odds ratio of being a moderate drinker $(<210 \mathrm{~g}$ alcohol per week for men and $<140 \mathrm{~g}$ alcohol per week for women) as opposed to being a non-drinker decreased linearly with increasing age.

\section{Alcohol-related harm in older people}

The European region of the World Health Organization has the highest impact of alcohol, with about $6.5 \%$ of the deaths (men $11.0 \%$; women $0.8 \%$ ) and $11.6 \%$ of the disability adjusted life years (DALYs, the years of life lost due to premature death and disability) (men 17.3\%; women 4.4\%) attributable to alcohol [18]. Most of these DALYs fall into the categories of neuropsychiatric disorders (with the overwhelming majority in alcohol use disorders), unintentional and intentional injuries, cirrhosis of the liver, cardiovascular diseases, and cancers. Alcohol, if consumed in a pattern of light regular drinking without heavy episodic drinking patterns, can also have a positive impact, mainly on ischaemic cardiovascular diseases. The above figures are net figures, taking into account the protective effects. Different dimensions of alcohol are responsible for causing harm [1]. The overall volume of consumption over time impacts on most disease categories, whereas irregular heavy drinking occasions in addition impact on injury and ischaemic conditions. The dose-response relationships vary. For diseases where alcohol has a protective relationship, there are $\mathrm{J}$ shaped curves, whereas for most other disease categories linear to exponential relationships prevail. For injuries, the acute level of BAC is the most important factor. To a lesser degree, the chemical composition of alcohol beverages may impact on health as well. This can be the case in methanol poisoning outbreaks, when methanol is added to spike alcoholic beverages, but also when production leaves too much acetaldehyde which is carcinogenic.

The review of alcohol consumption amongst elderly EU citizens published in 2009 and referred to above also suggested that there were some increases in alcohol-related hospital admissions and alcoholrelated deaths in older people, usually paralleling changes in alcohol consumption [16]. But, as with changes in alcohol consumption, it seemed that any trends amongst older people mirrored those of the population as a whole.

An illustration of this is changes in alcohol-related deaths (which include causes regarded as most directly due to alcohol consumption) in the United Kingdom. Two-thirds of the deaths occurred amongst men, and over four-fifths were due to alcoholic liver diseases and fibrosis and cirrhosis of the liver, conditions with usually a long time course. For men, the most marked increases occurred in the age group 55-74 years, with a stable or only slightly increasing trend in those 75 years and older.

In a comprehensive analysis, Jones et al. [19] estimated deaths in the United Kingdom, also including conditions that are partially due to alcohol. For both men and women, the estimated highest number of deaths from wholly alcohol-attributable conditions occurred in the age ranges 45-64 years, and was quite small amongst those dying at age 75 years or more. In the older age ranges, the estimated number of deaths from the partially attributable conditions became more important. However, this may be due to methodological artefact. Cancers and cardiovascular diseases are more common amongst older people, and even small relative risks and attributable fractions for such conditions will increase the number of deaths. Further, we do not have good estimates of relative risks and attributable fractions amongst older people, but they are likely to be considerably lower than such estimated for younger adults. Thus, applying estimates derived from younger populations is likely to inflate the number of partially attributable deaths. Although in absolute numbers there were an estimated higher numbers of alcohol-related deaths in older people, the proportion of all deaths that are alcohol-related declined with age. The estimated top three causes of alcoholrelated deaths amongst older people included liver diseases, malignant neoplasms and cardiovascular 
diseases [19], conditions for which there tend to be long durations between consumption and outcome, and long durations for benefit to accrue following reductions in alcohol-consumption [20].

Jones et al. [19] also analyzed hospital admission in the United Kingdom, and described similar findings. Amongst older people, estimated hospital admissions for wholly attributable conditions were quite low, compared with younger populations, whereas estimated admissions for partially attributable conditions were quite high. The estimated top three conditions amongst older people included mental and behavioural disorders due to alcohol, hypertensive disease and cardiac arrhythmias and, in the oldest age group, falls. But, again, the same problems of over-inflation of the estimates apply.

\section{Alcohol and well-being}

A number of cross sectional studies have suggested that light or moderate drinking might improve the quality of life amongst older people [21], although heavy drinking is associated with poorer quality of life $[22,23]$. However, cross sectional studies cannot infer causation and self-reported measures may not reflect an accurate measure of performance [24].

In the UK based MRC Trial of the Assessment and Management of Older People in the community described above, never and ex-drinkers were less likely to live with a spouse and more likely to live alone or with other people compared with drinkers [17]. Drinkers were also more likely to have contact with other people. Never and ex-drinkers were less likely to be home-owners, whereas those that drank were more likely to be home-owners.

In both sexes never drinkers were likely to be the most deprived and those that drink in moderation were likely to be the most affluent. When subjects were asked whether they have financial difficulties, those that did tended to be ex- and moderate drinkers. Heavier drinkers tended to have no financial hardship.

Participants completed the Mini Mental State Examination (MMSE). The MMSE is a widely used test of cognitive function and has been shown to be both valid and reliable [25]. Those people who scored below 17 were designated severely cognitively impaired. Those who scored between 17 and 23 were considered mildly impaired, and those above 23 were judged to have no impairment. A clear gradient was observed with current drinking being more common amongst those who were not cognitively impaired. When subjects were asked about whether they had difficulties undertaking everyday activities such as cooking, washing and walking, again the two drinking groups were less likely to answer yes. Drinkers were also less likely to have had falls, more likely to have a good perception of their general health, and more likely to consider themselves physically active. Diabetes was more common in the nondrinking groups, but not previous heart attack. Little association was observed between alcohol intake and number of different medications used.
Participants completed the 15 -item version of the Geriatric Depression Scale (GDS) [26]. A cut-off point of 6 or more is commonly used to indicate depression. Depression tended to be slightly higher in the non-drinking groups for women, but otherwise very little association was observed. By contrast, reported anxiety was lower in the never drinkers and higher in the ex- and current drinking groups. A clear dose-response relationship was found for number of positive responses to anxiety questions and increasing alcohol consumption.

Little association was observed between alcohol intake and death or separation from a loved one in the last year. However, reporting a serious illness in a loved one or moving residence was more common in the drinking groups.

After adjustment for other variables, the odds of being a moderate drinker in females was $0.37(95 \% \mathrm{CI}$ 0.32-0.42) compared with males. In addition, those people above 80 years of age, those with a higher Carstairs score (an index of deprivation based on four variables available from the 1991 census: overcrowding, social class of head of household, car ownership and unemployment) [27], those that had a poor general health perception, and those that had difficulty with everyday activities were also statistically significantly less likely to be moderate drinkers. Drinkers also had significantly less cognitive impairment, were more likely to be smokers, were more likely to have experienced a serious illness in a loved one, were more likely to have suffered a heart attack, and had higher Body Mass Index (BMI). Anxiety was associated with drinking with an increased odds of 1.33 (95\% CI 1.08-1.63). Depression (GDS score) was not found to be an independent predictor in this model. Models run separately for men and women did not affect results to any large extent.

Disruption of lifestyle such as retirement and decreased social activity are thought to be some of the main contributory factors among people who develop alcohol problems later in life.

Isolation and loneliness in old age can lead to increased drinking, but the above study suggested that those that have a regular drink are, in fact, those that are also more likely to be living with a spouse. Other studies have also observed that the stresses of ageing, such as widowhood and retirement, are not associated with increased problem drinking [28]. A study of 2641 community-dwelling non-disabled people aged 65 years and over registered at a general practice in London found that after adjustment for age, sex, income, and educational attainment, living alone was associated with multiple falls, functional impairment, poor diet, smoking status, risk of social isolation, but not hazardous alcohol use [29].

A systematic review of behavioural determinants of healthy aging identified alcohol use as protective [30]. For example, a longitudinal study of non-demented people aged 65 years and older noted that those who drank five or more drinks a year (alcohol content of drink not defined) and without alcohol- 
related problems had improvements over the four year follow-up period for activities of daily living, instrumental activities of daily living and performance based physical function compared with those who drank less than five drinks a year or who had alcohol-related problems [31].

In their systematic review of the health-related effects of alcohol use in older persons, Reid et al. [32] found four studies in which an average weekly consumption of either $\geq 10$ drinks per week (alcohol content of drink varied across countries and not defined), a history of heavy use, or an increasing number of drinks consumed per occasion were associated with greater risk for functional disability when compared with non-drinkers or participants with no history of heavy drinking. One additional study found that $\geq 14$ drinks per week increased risk for functional disability among men, but not women. Exposure-outcome associations were not demonstrated in six studies. In contrast, two investigations found that increasing alcohol consumption decreased risk for functional disability.

The Alameda county study [33] which investigated participants aged 65 to 89 years at 19 years followup, found that those who consumed between 1-60 drinks per month at baseline (alcohol content of drinks not defined) were three times as likely to show high physical functioning than be dead compared with abstainers, and over twice as likely to show high as opposed to low or moderate functioning for those still alive. Study participants consuming more than 60 drinks per month were more likely to be dead as opposed to be high functioning than the lighter drinkers and more likely to have low or moderate as opposed to high function than the lighter drinkers amongst those still alive, although in both cases, the results did not reach statistical significance.

Lang et al. [34] reported on the results of two similar longitudinal studies that followed up 13333 individuals aged 65 and older for 4 to 5 years, studying functioning and mortality at follow-up compared with alcohol consumed at baseline - the Health and Retirement Study (HRS) from the US and the English Longitudinal Study of Aging (ELSA). The alcohol consumption reference category was more than none to one drink per day (alcohol content of drinks not defined). Odds ratios (ORs) in the more than one to two drinks per day range were not significantly different from the reference category, for disability outcomes alone or combined with mortality, in any of the analyses, controlling for baseline confounders. In the pooled model, the ORs in subjects drinking more than one to two drinks per day for the outcomes of interest were $0.96(95 \%$ CI 0.78 1.21) for activity of daily living problems (ADLs), 0.75 (95\% CI 0.56-0.99) for instrumental activity of daily living problems (IADLs), and 0.82 (95\% CI 0.64-1.05) for poor cognitive function.

For the HRS data set, combined mortality and functioning outcomes produced ORs in subjects drinking more than one to two drinks per day of
0.93 (95\% CI 0.68-1.28) for ADL problems or mortality, 1.06 (95\% CI 0.76-1.49) for IADL problems or mortality, and 1.00 (95\% CI 0.73-1.37) for decline in cognitive function or mortality. In the ELSA models, the corresponding ORs were 0.94 (95\% CI 0.69-1.27) for ADLs, 0.72 (95\% CI 0.49-1.05) for IADLs, and 0.93 (95\% CI $0.63-1.37$ ) for poor cognitive function. Modelling of risks separately for men and women produced similar estimates but with limited power, and the risks of disability at various levels of alcohol consumption were similar in men and women.

The methodological problem with many of the studies that relate alcohol consumption to measures of well-being, or its converse, for example, functional disability, is whether or not all potential confounders have been measured and controlled. And, this does not seem to be the case.

The fact that non-drinkers tend to show poorer outcomes compared with the lighter drinkers could be due to the sick-quitter effect (that is people who are ill have stopped drinking because of their illness) or simply reflect the fact that lighter drinkers are wealthier, healthier and better socially integrated than non-drinkers or heavy drinkers. For example, in the UK based MRC Trial of the Assessment and Management of Older People in the community, the odds ratio of being a moderate drinker $(<168$ $\mathrm{g}$ alcohol per week for men and $<112 \mathrm{~g}$ alcohol per week for women) as opposed to being a non-drinker decreased linearly with increasing deprivation [17].

Thus, whilst it might be observed that, compared with non-drinkers, light older drinkers (up to two drinks a day) experience better well-being, whether or not, or the extent that this is due to alcohol or to potential confounders is not known.

\section{Alcohol and health}

For the adult population as a whole, both the volume of lifetime alcohol use and a combination of frequency of drinking and amount drunk per occasion increase the risk of alcohol-related harm, largely in a dose-dependent manner [11].

Alcohol is an intoxicant affecting a wide range of structures and processes in the central nervous system which, interacting with personality characteristics, associated behaviour and sociocultural expectations, are causal factors for intentional and unintentional injuries including interpersonal violence, suicide, homicide, and drink-driving fatalities.

Alcohol is neurotoxic to the brain leading, in middle age, to reduced brain volume. Alcohol is a dependence-producing drug, similar to other substances under international control, through its reinforcing properties and neuroadaptation in the brain. It is an immunosuppressant, increasing the risk of communicable diseases, including pneumonia and tuberculosis. Alcoholic beverages are classified as a carcinogen by the International Agency for Research on Cancer, increasing the risk of cancers in a linear dose-response relationship. Acetaldehyde, 
which occurs in alcoholic beverages as well as being produced in ethanol metabolism, is a potential pathway for cancer risk. Alcohol has a bi-form relationship with coronary heart disease. In low and apparently regular doses (as little as $10 \mathrm{~g}$ every other day), alcohol appears to be cardio-protective, but at high doses, particularly when consumed in an irregular fashion, it is cardio-toxic. It should be noted that considerable concern remains about the extent to which the observed cardio-protection is due to systematic definition errors, drinking patterns and genetic factors, and the extent to which the size of the protective effect is overestimated.

\section{Injuries}

A systematic review of risk factors for low bone mineral density (BMD) in healthy men aged 50 years or older, found fifteen studies (five longitudinal, ten cross-sectional) that assessed BMD and moderate alcohol consumption (level not defined) [35].

There was inconsistent evidence from the crosssectional studies: five studies found a positive association between moderate alcohol consumption and BMD at the hip and/or lumbar spine, while five others did not find an independent association at either BMD site. Moderate alcohol intake was not predictive of the rate of bone loss in several longitudinal studies. On the other hand, a cross European study found a positive association between alcohol use and osteoporotic mandibular bone loss in middle and older aged women [36].

Similarly, there are mixed findings between alcohol intake and the risk of fractures, with some studies finding no relationship [37], and others finding that light drinking protects against the risk of fractures, whilst problems drinking increases the risk of fractures [38].

In their systematic review of the health-related effects of alcohol use in older persons, Reid et al. [32] found 26 studies, four of which found an increased risk for falls or fall injuries associated with exposures ranging from daily use to an average weekly consumption of $\geq 21$ drinks when compared with non-drinkers or individuals consuming $\leq 1$ drink per week (alcohol content of drinks not defined). Twenty-one studies found no association between increased alcohol use and falls or fall injuries. In contrast, one study found that participants who reported daily use of alcohol had decreased risk for falls compared with non-drinkers.

As might be expected, older drivers with a diagnosis of alcohol dependence have a higher relative risk of a motor vehicle accident than drivers without such a diagnosis [39].

Some studies [40] have suggested that drinkers have an increased risk of death from a motor vehicle accident than non-drinkers, but such studies often suffer for failing to take into account the amount of driving (it may be that drinkers drive more than non-drinkers and are thus more likely to have an accident).
Data from Great Britain show that drink drive accidents amongst drivers aged 60 years or over are a tiny proportion $(4 \%)$ of all accidents per licence holder, even accounting for distance driven [41].

\section{Dementia and cognitive decline}

A systematic review of alcohol, dementia and cognitive decline in the elderly identified 26 studies [42]. Fifteen papers (14 studies) found one or more statistically significant association with alcohol intake; three studies found an increased risk for either vascular dementia (VaD), Alzheimer's disease (AD) (when place of residence only was controlled for), dementia as a whole or poorer performance on a visual reproduction test. The remaining 11 studies were positive, with one finding that reduced cognitive function was associated with abstinence before age 60 . The reported results from all included studies as relative risks, odds ratios or hazard ratios were collated for meta-analyses in accordance with their outcome: dementia, AD, $\mathrm{VaD}$ and cognitive decline respectively. The combined risk ratios for each of the four outcomes were dementia 0.63 (95\% CI $0.53-0.75)$, AD 0.57 (95\% CI 0.44-0.74), VaD 0.82 (95\% CI 0.50-1.35) and cognitive decline 0.89 (95\% CI 0.67-1.17), respectively with alcohol intake.

To summarise, alcohol consumption appears to be protective for dementia and $\mathrm{AD}$, but there is no evidence of a protective effect against $\mathrm{VaD}$ or impaired cognitive function. With regard to cognitive function, results for optimal consumption were mixed, either above/below or equal to one drink a month or day (in subjects with cardiovascular disease or diabetes, one-two drinks per week). For AD, optimal amounts were a weekly consumption of wine, onesix or more than two drinks per week, or more than three drinks/250-500 $\mathrm{ml}$ per day (usually wine), or where studied by gender, one-three per day in males. For dementia, benefit was shown for more than one drink per day, weekly or monthly wine consumption, $250-500 \mathrm{ml}$ (usually wine) or more than three drinks per day and from 1-28 units per week. For $\mathrm{VaD}$, one-three drinks per day in males were beneficial. Overall, there was no close agreement among studies as to the optimal level of consumption and although most studies reported that light to moderate consumption was best with regard to incident decline or dementia the classification of light to moderate drinking varied very widely.

With regard to the alcohol type, 12 studies looked at beers, wines and spirits separately although for two, only wine was consumed in any quantity by the study population. One study reported examining red and white wine separately in their questions but did not report in detail regarding this. In four papers (two from the same population but with a different follow-up), wine intake was found to significantly reduce the risk.

In their systematic review of 49 studies, Panza et al. [43] concluded that light to moderate drinking is not harmful to cognition and dementia, although it 
was not possible to define a specific beneficial level of intake. In their systematic review of the health-related effects of alcohol use in older persons, Reid et al. [32] found ten studies with an increased risk of cognitive impairment associated with either a history of alcohol abuse, heavy drinking or an average weekly consumption of $\geq 10$ drinks when compared with individuals without histories of alcohol abuse or heavy drinking or non-drinkers (alcohol content of drinks not defined). In two of the studies, the results varied according to the methods used to measure alcohol exposure. In one investigation, an increased risk for poorer cognitive function was found among participants who screened positive on a standard problemdrinking questionnaire as compared with screen-negative subjects, but was not evident when subjects' average daily intake of alcohol was analyzed. Similarly, one study demonstrated that increased risk for cognitive impairment was present among participants with histories of alcohol dependence, but the effect was not seen using subjects' average weekly alcohol exposures. Twenty-one studies found no relationship between cognitive impairment and alcohol exposures that ranged from any use to a history of heavy drinking to an average weekly consumption of $\geq 24$ drinks. Finally, one study reported that consuming 14-35 drinks per week (as compared with non-drinkers) was associated with improved cognitive function in older women but not men.

There is some evidence from cross-sectional [44] and longitudinal [45] studies that moderate consumption, as opposed to abstention and heavier drinking, decreases the risk of depression in older people. This is likely to be due to the relationship between drinking and a more active and sociable lifestyle.

\section{Cardiovascular disease and other conditions}

Epidemiologic data from more than 100 studies across 25 countries consistently demonstrate a U- or $\mathrm{J}$-shaped association between alcohol consumption and coronary heart disease [46], also amongst older adults [47, 48]. Gronbaek et al. [49] in their study of Danish women and men aged $\geq 50$ years found that the effect of alcohol intake on mortality did not differ between middle-aged and elderly subjects. There was a U-shaped risk function in both age-groups, suggesting a reduced mortality risk among subjects with light alcohol intake as compared to abstainers or those who consume more than an average of four drinks per day.

There have been many methodological critiques of the relationship between alcohol consumption and ischaemic heart diseases [50]. In general, though, it does seem that there is a beneficial effect, although the size of the effect may have been overestimated. It also needs to be remembered that relative risks for risk factors for coronary heart disease converge towards 1.0 with increasing age [51], including alcohol [52]. The Honolulu heart study found that comparing drinkers with non-drinkers, the relative risk converged towards 1.0, with increasing age, such that there was no evidence for a protective effect in men aged 75 years or older [53]. Further, in this age group, there is an increased over-recording of coronary heart disease on death certificates. The Framingham Heart Study found that over-recording of heart disease on death certificates increased exponentially with age, such that at an age of death of 85 years or more, over-recording was estimated to be doubled [54].

Few studies of the relation of alcohol intake to lower-extremity arterial disease (LEAD) have included clinical events and objective measurements repeated longitudinally. As part of the Cardiovascular Health Study, a study of older adults from four US communities, 5635 participants reported their use of beer, wine, and spirits yearly [55]. Incident LEAD was identified by hospitalization surveillance. Technicians measured ankle-brachial index 6 years apart in 2298 participants. A total of 172 cases of LEAD were documented during a mean of 7.5 years of follow-up between 1989 and 1999. Compared with abstention, the multivariable-adjusted hazard ratios were $1.10(95 \% \mathrm{CI} 0.71-1.71)$ for $<1$ alcoholic drink per week, 0.56 (95\% CI 0.33-0.95) for $1-13$ drinks per week, and 1.02 (95\% CI $0.53-1.97)$ for $\geq$ 14 drinks per week ( $\mathrm{p}$ for quadratic trend $1 / 40.04$ ). These relations were consistent within strata of sex, age, and apolipoprotein E genotype, and neither lipids nor inflammatory markers appeared to be important intermediates. Change in ankle-brachial index showed a similar relation ( $\mathrm{p}$ for quadratic trend $1 / 40.01$ ). Thus, an alcohol consumption of 1 13 drinks per week in older adults may be associated with lower risk of LEAD, but heavier drinking is not associated with lower risk.

The literature suggests that alcohol has a complex non-linear relationship with ischaemic stroke, with low or moderate intakes associated with reduced and high intake with increased risk; in contrast haemorrhagic stroke has a linear association with increasing alcohol intake, some studies of older people suggest a linear dose response relationship between alcohol consumption and risk of total and ischaemic stroke [56].

Alcohol is shown to reduce the risk of diabetes in both older men and women at least up to a consumption of 20-30 g alcohol per day [57, 58].

Individuals with the metabolic syndrome, a condition characterized by disturbed glucose and insulin metabolism, dyslipidemia, hypertension, and central obesity, are at greater risk of developing type 2 diabetes mellitus and cardiovascular disease, but there is evidence that alcohol intake is not related to the risk of metabolic syndrome in older people $[59,60]$.

There is some evidence that alcohol increases the risk of age-related macular degeneration [61].

\section{Cancers}

Alcoholic beverages are classified as a carcinogen by the International Agency for Research on Cancer, increasing the risk of cancers of the oral cavity and 
pharynx, oesophagus, stomach, colon, rectum and breast in a linear dose-response relationship [62]. Acetaldehyde, which occurs in alcoholic beverages as well as being produced in ethanol metabolism, is a potential pathway for cancer risk, with a global average of lifetime cancer risk from alcoholic beverages of 7.6 in 10000 [63]. The amount of drinking 15-20 years ago reflects the formation of cancer. Thus, if people quit drinking, their relative risks compared to lifetime abstainers decrease slowly, and only after $15-20$ years is a level similar to lifetime abstainers reached [20].

For countries like Italy or France, which in 2002 had high alcohol-attributable cancer proportions within all alcohol-attributable deaths (both > 30\%), this also reflected the success of their alcohol policies [18]. As consumption and total alcohol-attributable diseases and injuries have been going down over the past 30 years, the relative weight of alcoholattributable cancers went up.

\section{Interaction with medications}

Older adults who drink alcohol and who take medications can be at risk for a variety of adverse consequences depending on the amount of alcohol and the type of medications consumed [64]. Types of risks include increased blood alcohol levels (BALs), increased and/or decreased drug metabolism, disulfiramlike reactions, exacerbation of therapeutic effects and adverse effects of medications, and interference with the effectiveness of medications. These risks may cause disorders such as liver and gastrointestinal disease, sedation, dizziness, problems with coordination leading to falls and injuries, gouty flares, therapeutic failure or overdose, hypotension, hypertension, insomnia, worsening of depression, and poor control of seizure disorders and diabetes mellitus.

A number of studies have investigated the prevalence of alcohol/medication interactions in older adults. Using data from 83321 participants aged 65 to 106 years in the Pennsylvania PACE program (a state-funded program providing prescription benefits to older persons with low to moderate incomes), the researchers found that $19 \%$ of those consuming alcohol (20.3\% of the sample) took medications that could have negative interactions with alcohol [65].

In another study among 311 drinkers (mean [SD] age, 83 [6] years) in 3 retirement communities in suburban Milwaukee, Wisconsin, 38\% used drugs that could have negative interactions with alcohol [66].

A third study among a sample of 667 communitydwelling older adults (mean [SD] age, 74 [7] years) living in northeast New York estimated that $25 \%$ of them drank alcohol and took medication that could negatively interact with alcohol [67].

A fourth study, using data from the Italian Group of Pharmacoepidemiology in the Elderly study, found that the prevalence of adverse drug reactions among 22,778 older hospitalized persons (mean [SD] age, 70 [16] years) was 3.7\% among abstainers and $4.1 \%$ among those who drank $<40 \mathrm{~g}$ of alcohol per day [68]. After adjusting for potential confounders, moderate drinkers were $24 \%$ more likely to experience an adverse drug reaction compared with abstainers.

A fifth study among 166 older adults (mean age 73 years; age range 60-93 years) in primary care settings in Los Angeles, California, considered at-risk drinkers and found that more than $70 \%$ of them were believed to be susceptible to problems because of the amount of alcohol they drank combined with the medications they took [69].

\section{Overall mortality}

In their systematic review of the health-related effects of alcohol use in older persons, Reid et al. [32] found four studies which reported that increased alcohol use was associated with a greater risk for all-cause mortality. As compared with nondrinking men, older men who reported a history of heavy drinking were at an increased risk for all-cause mortality. Another investigation found that an average weekly consumption of $\geq 14$ drinks (relative to nondrinkers) increased risk for death among older men but not women (alcohol content of drinks not defined). This level of exposure ( $\geq 14$ drinks per week) was also associated with an increased risk for allcause mortality when compared with non-drinkers in one of three population-based cohorts. Finally, consumption of $\geq 29$ drinks per week as opposed to no alcohol use was associated with an increased risk for mortality among older male physicians.

Thirteen studies found no association between increased alcohol use and all-cause mortality. In contrast, four studies demonstrated a protective effect from increased alcohol consumption. A decreased risk for all-cause mortality was observed among participants reporting an average weekly consumption of $\geq 14$ drinks in two of three populationbased cohorts. Individuals who reported an average weekly consumption of $\geq 28$ drinks per week and were judged to be at high (but not low) cardiovascular risk were found to have a decreased risk for all-cause mortality when compared with non-drinkers. One study demonstrated that an average weekly consumption of $\geq 28$ drinks was associated with a decreased risk for mortality among men when compared with non-drinkers. In this investigation, the highest exposure category for older women (15-28 drinks per week) was not related to improved survival. Finally, participants who reported a history of moderate or heavy alcohol use had improved survival when compared with all other categories of exposure in one cohort study.

Data from longitudinal studies in six European countries found that any alcohol use was protective of the risk of death amongst older people followed up for five years (hazard ratio $0.81,95 \%$ CI $0.71-0.93$ ) [70]. Similar findings were apparent for a ten-year follow-up in another study of eleven European countries (hazard ratio $0.78,95 \% \mathrm{CI}, 0.67-0.91$ ) [71]. 


\section{Alcohol policy and older people}

Although there are many reviews of the impact of alcohol policy [72], none have specifically considered the impact of alcohol policy on older as opposed to younger people. Of the effective alcohol policies summarized in a recent WHO review, the policy option that is likely to have the biggest impact on older people is price [11]. Restricting the availability of alcohol, through reductions in outlet density or days and hours of sale also reduce harm, although this has been most evaluated with its impact on alcoholrelated violence and injuries.

\section{Price of alcoholic beverages}

Drinkers respond to changes in the price of alcohol as they do to changes in the prices of other consumer products. When other factors are held constant, such as income and the prices of other goods, a rise in alcohol prices leads to less alcohol consumption and less alcohol-related harm, and vice versa [73]. A meta-analysis of 132 studies found a median price elasticity for all beverage types of -0.52 in the short term and -0.82 in the long term, elasticities being lower for beer than for wine or spirits [74]. An elasticity of -0.52 means that for every $10 \%$ increase in price, consumption would fall by $5.2 \%$. Another meta-analysis of 112 studies found mean price elasticities for beer of -0.46 , for wine of -0.69 , and for spirits of -0.80 [75].

Beverage elasticities are generally lower for the preferred beverage (beer, spirits or wine) in a particular market than for the less-preferred beverages, and tend to decrease with higher levels of consumption. Consumers tend to shift to more expensive beverages if relative prices decrease, either within the same beverage category or across beverage categories. If prices are raised, consumers reduce their overall consumption and tend to shift to cheaper beverages, with heavier drinkers tending to buy the cheaper products within their preferred beverage category.

Price increases reduce the harm caused by alcohol, which also indicates that heavier drinking has been reduced [73]. Cirrhosis mortality is responsive to small changes in price: in the United States, increases in taxes have been shown to lead to an immediate reduction, which doubles over the long run [76]. More recent estimates found that a $10 \%$ increases in tax in the United States was associated with a $32 \%$ decrease in the death rate from cirrhosis [73].

Consistent with this, studies have reported that increases in the price of alcohol result in a reduction in heavy drinking and alcohol dependence. A study of survey data of 43000 adults in the United States found a price elasticity for heavier drinking of -1.325 $(\mathrm{p}=0.027)$, for physical and other consequences of drinking of $-1.895(\mathrm{p}=0.003)$, and for alcohol dependence of $-1.487(p=0.012)$ [77]. Studies in Alaska found statistically significant reductions in the numbers and rates of deaths caused by alcoholrelated disease beginning immediately after alcohol tax increases in 1983 and 2002 [78].

\section{Prevention and education programmes}

While the provision of information and education is important to raise awareness and impart knowledge, by themselves information and education do not lead to sustained changes in alcohol-related behaviour [11]. Education can, however, be a tool for awareness and raising support, and an important feature of a broader alcohol strategy. Campaigns and health education messages funded by the alcohol industry seem to have negative effects, serving to advance the interests of both the industry's sales and public relations. Although warning labels have little impact on behaviour, they are important in helping to establish a social understanding that alcohol is a special and hazardous commodity. Most studies of educational approaches have evaluated impact amongst younger people, and the impact of educational approaches amongst older people is not known.

There is some evidence that community-based programmes can have an impact on creating safer drinking and living environments and reducing underage drinking, harmful patterns of drinking and drinkdriving accidents, although they can be costly to implement and sustain [11]. Such programmes should include controls on venues for the sale and consumption of alcohol, other regulations reducing access to alcohol, enhanced law enforcement and surveillance, and the development of community organization and coalitions supported by education and information campaigns, media advocacy, counter-advertising and health promotion.

As with educational approaches, most studies of community-based programmes have evaluated impact amongst younger people, and the impact of such approaches amongst older people is not known.

Alcohol use can increase the risk of absenteeism and poor performance at work, and structural factors at work can increase the risk of harmful alcohol use [79]. The available evidence suggests that workplace-based interventions have some limited impact in reducing alcohol-related harm, and could thus be implemented as pre-retirement measures.

\section{Early identification and brief interventions amongst older people}

A systematic review of the utility of self-report alcohol screening instruments in the elderly identified 18 studies [80]. Factors affecting the performance of alcohol screening instruments include the culture, the clinical setting, patient characteristics and the prevalence of alcohol use disorders (AUDs) in the population being studied. Factors affecting the overall usefulness of a screening instrument should also take into account patient acceptability and its ease of use.

The vast majority $(72 \%)$ of studies reviewed were from the US and results may not be generalizable to other cultures. Furthermore, a large proportion of US studies (39\%) have focussed on US veterans (people who have served in the armed forces) popu- 
lations, a specific patient group with a well-established higher prevalence of AUDs than the general population.

The majority $(72 \%)$ of studies focussed on community dwelling and outpatient populations. The documented higher rates of AUDs in elderly hospital inpatients and elderly Emergency Department attendees, with higher rates of medical comorbidities and greater associated economic burden, should direct further research to these groups. Elderly people with psychiatric illness are also an understudied group, and carry a high risk of AUDs. While CAGE questionnaire sensitivity has been shown to be very poor in this group, the AUDIT-5 (Alcohol Use Disorders Identification Test) has had promising results to date. Overall, however, AUDIT-5 utility has been examined in only one study, whereas CAGE utility has been examined in several studies involving over 6000 individuals and yielding a median sensitivity of $66.5 \%$ and a median specificity of $89 \%$. No study focussed on elderly people with cognitive impairment, a particularly vulnerable group where a valid screening instrument is needed.

The Michigan Alcohol Screening Test (MAST) and variations of this screening instrument were found to be robust screening instruments in these elderly populations, but less research has focussed on the MAST than the CAGE questionnaire. Furthermore, the MAST questionnaire, and its variations, may take up to 5 minutes to complete, making it more difficult to apply and possibly less patient acceptable than the CAGE.

All screening instruments generally performed well in populations with high prevalence rates of AUDs.

A more recent systematic review of eight studies [81] showed that when using pen-and-paper alcohol screens in primary care, the selected studies in the 60 years and over age-group gave similar findings to those in the more general adult population.

Using traditional definitions of hazardous and harmful drinking, the AUDIT and AUDIT-C appeared superior screens to the CAGE and various forms of the MAST. From the limited data, the AUDIT-C appeared as good if not better than the AUDIT.

Optimum cut-offs for both these tests were difficult to ascertain from the data, and it is certainly possible that lower cut-offs than eight for the AUDIT and three for the AUDIT-C might be more efficient in the 60 and over age-group. In comparison, one of the few pieces of research on screening elderly psychiatric patients suggested that both the AUDIT and a cutdown version, the AUDIT-5, were equally good at detecting hazardous and harmful drinking, and both were superior to the CAGE for this indication.

A systematic review of 27 systematic reviews provided a considerable body of evidence supportive of the effectiveness of brief interventions for hazardous and harmful alcohol consumption in reducing alcohol consumption, mortality, morbidity, alcoholrelated injuries, alcohol-related social consequences, healthcare resource use and laboratory indicators of hazardous and harmful alcohol consumption [82]. Six systematic reviews demonstrated that interventions delivered in primary care are effective in reducing alcohol-related negative outcomes. Three systematic reviews specifically focusing on the use of brief interventions in emergency care found limited evidence for the effectiveness of brief interventions for hazardous and harmful alcohol consumption in emergency care settings. A further review presented inconclusive evidence of the effectiveness of brief interventions in inpatient and outpatient settings. A systematic review of brief interventions for alcohol misuse in the workplace presented limited and inconclusive findings for the effectiveness of interventions in this setting. Brief interventions are effective in reducing alcohol consumption in both men and women.

The majority of included primary evidence was drawn from adult populations with an age range of 12 to 70 years. Therefore, brief interventions for adults have been shown to be effective amongst adult populations. In the identified systematic reviews, no studies particularly looked at brief interventions amongst older people per se. However, the limited literature suggests no differing outcomes between older and middle-aged populations [83-85].

A randomized controlled trial of health risk appraisal in British general practice promoting health in older people included an intervention that led to computer-generated individualised written feedback to participants and general practitioners, integrated into practice information-technology systems [86]. All primary care staff received training in preventative health in older people. The main outcome measures were self-reported health behaviour and preventative care uptake at 1-year follow-up. Intervention group respondents reported slightly higher pneumococcal vaccination uptake and equivocal improvement in physical activity levels compared with controls. No significant differences were observed for any other categories of health behaviour, including no or moderate alcohol use, or preventative care measures at 1-year follow-up.

\section{DISCUSSION AND CONCLUSIONS More information is needed on alcohol and older people}

Compared with younger people, there is a paucity of data describing alcohol use, alcohol-related harm and effective policy and preventive approaches amongst older people. However, from this review, compared with their younger counterparts, older people do not suffer from disproportionally higher levels of harm. In general, they drink less than their younger counterparts, drink less hazardously, and suffer less harm. Within their drinking volumes, their drinking patterns, determinants and associations appear no different from the younger adult population.

What is clear though is that, when compared with younger people, there is a dearth of literature on alcohol and older people, and often poor sampling of 
older people and less reporting about the drinking habits of older people in national surveys. It is thus clear that more research and better data on alcohol and older people are needed.

Although the pharmacokinetics of alcohol amongst older people might suggest that at any given alcohol intake, higher BACs are reached, few data are available to state whether or not there are any substantive or special factors with regard to alcohol-related health outcomes.

In their systematic review of the health-related effects of alcohol use in older persons, Reid et al. [32] noted that $17(20 \%)$ of the 84 studies demonstrated harm associated with increased alcohol exposures, $59(70 \%)$ found no association between increased alcohol use and any of the selected outcomes (all cause-mortality, cognitive impairment, disability and falls), and eight $(10 \%)$ reported benefit from greater alcohol use.

Indeed, a number of studies suggest that older people who do drink have a better quality of life and less risk of dying than those who do not drink. The level of alcohol consumption that shows benefit is uncertain, but Kirchner et al. [22] found similar health parameters (e.g. perceived health, depressive/anxiety symptoms, and social support) between those who drank 17 drinks and those who consumed 8-14 drinks weekly.

Most studies show that drinkers of alcohol have better life outcomes and less risk of dying than nondrinkers. For those who do drink, there is certainly no evidence that those who consume $20 \mathrm{~g}$ alcohol per day are any worse or any better off than those who drink less. Of course, this may just mean that those who are healthier, wealthier and better socially adjusted are more likely to be light drinkers than abstainers or heavy drinkers.

\section{Alcohol policy, interventions and older people}

The specific impact of alcohol policy on older people has not been studied. However, there is no reason other than to assume that those policies that have immediate effect in reducing the consumption and burden of the middle aged, would not also work equally effectively for older people. Further, although there is scarce evidence, it seems that older people respond equally well to screening instruments and brief interventions as do younger adults. Thus, for older people who are at risk of or who are currently experiencing negative alcohol-related outcomes, the implementation of existing evidence based alcohol policy should be business as usual.

\section{Focus on the middle aged}

The GENACIS study convincingly demonstrated that, during the early 2000s, the middle aged (those aged 50-65 years) drank frequently and with high volume, and that over the early adult age these parameters of drinking did not decrease [15].

Most alcohol-related deaths occur amongst the middle aged, and it is in this age group that, where a country's overall alcohol consumption is increasing, the steepest increases in alcohol-related deaths occur.
Data from Altay and Tomsk regions of Russia also show that, although alcohol-related deaths amongst older people (aged 55-74 years) were very high and responsive to socio-economic changes, a much higher proportion of deaths in the 1990s amongst those aged $15-54$ years $(59 \%$ of men and $33 \%$ of women) were due to alcohol than amongst those aged 55-74 years ( $22 \%$ of men and $12 \%$ of women) [87].

This suggests that alcohol policy should target the middle age, since policy can have an immediate impact in reducing alcohol-related deaths amongst the segment of the population in which they are most occurring [88], thus preventing alcohol related problems amongst the future older population. Many alcohol-related conditions, and in particular cancers, have long latency period, with some reductions in risk occurring soon after changes in consumption, but with the full extent of reductions in risk not occurring until some 15-20 years after reductions of alcohol use [20]. Modelling evidence in the United Kingdom has demonstrated that increasing taxes on alcohol and introducing a minimum price per gram of alcohol have immediate impact in reducing alcohol-related harm and mortality, with incremental gains achieved over a ten year time span [89].

Further, there is some evidence that heavier drinking cohorts during times of less comprehensive and stricter alcohol policies continue their heavier drinking patterns as they age [90].

It is becoming increasingly recognized that it is lifetime exposure to alcohol that is of importance in increasing risk of negative health outcomes. This has been well demonstrated in the relationship between lifetime exposure and reductions in brain gray matter volume [91], and increases in female breast cancer [92] and overall death [93]. Lifetime attributable risk of dying from alcohol-related death for men and women living in Australia [94] has been shown to increase linearly with increasing alcohol consumption, even at very low doses of alcohol per day.

Given the importance of lifetime exposure, the maintenance of high frequency and high volume drinking of the middle age referred to above is likely to lead to upward pressure on the ill-health of the growing number of older people. For this reason, if a country wanted to diminish the risk of alcohol-related ill-health continuing into older age, the target of alcohol policy should be also the middle aged [88].

\section{Recommendations}

The public health implications arising from the present systematic review on alcohol and older people can be summarized in the recommendations listed below:

\section{For existing older people}

1. More and better data and reporting, standardized across Europe, is needed on alcohol use, consumption patterns and alcohol-related consequences amongst older people, including those aged 65 years plus and those aged 80 years plus, including also measuring lower levels of alcohol consump- 
tion and potential alcohol related consequences and health outcomes. This should include both longitudinal surveys and the incorporation of alcohol-related questions in studies of aging.

2. More and better research is needed on the absolute risk of alcohol over the life course and to older people including those aged 65 years plus and those aged 80 years plus.

3. More and better research is needed of the differential impact of existing alcohol policy measures, preventive programmes and health care based interventions on older people, including those aged 65 years plus and those aged 80 years plus.

4. Although there is no specific evidence, there is no reason to think other than that existing alcohol policy measures, particularly those that impact on economic and physical availability, will also work amongst older people and should thus continue to be implemented.

5. Although there is limited evidence, screening and brief intervention programmes for hazardous and harmful alcohol consumption seem to work just as well for older as opposed to younger people and should be implemented also for the older populations, supported by enhanced training for primary care providers.

\section{For future older people}

6. To reduce the alcohol-related burden in older people over the next 20 and coming years, alcohol policies and programmes should target and be intensively implemented toward the existing middle aged to get them urgently to drink less.

7. Given that alcohol-related harm is likely to increase amongst older people over the coming years, alcohol policies and programmes should become integral parts of strategies to promote healthy ageing.

According to a lifecycle approach, it should be recommended to overcome the distinction between current and future older people, hopefully aiming at the prevention of future problems in older people according to a reduction in alcohol consumption among those who are middle-aged at present, but also increasing the capacity to deal with alcohol-related problems in the present older people by early detection of hazardous level of alcohol use.
A renewed approach is needed, hopefully oriented at increasing research and base of evidence, in order to overcome the mistaken belief that older persons have little to gain from diagnosis and treatment of alcohol-related problems, as well as to give to older people the right to appropriate and valuable interventions supporting healthier lives and a more active ageing perspective.

\section{Acknowledgments}

The VINTAGE project Good Health into Older Age is a project funded by the Executive Agency for Health and Consumers, under the European Commission Second Programme of Community Action in the Field of Health 2008-2013 (Grant Agreement no. 20081203).

The authors wish to thank Gino Farchi and Mats Halgren who reviewed the VINTAGE reports, and Ann Hope as independent evaluator of the whole project.

We are particularly indebted to the other components of the VINTAGE project Working Group, who have been involved in a consultation process reviewing, commenting and contributing to the different drafts of this review, providing precious advice and support.

Finally, a special thank to Rosaria Russo for the technical and administrative support, and to Pierfrancesco Barbariol and Lorenzo Fantozzi for the time spent on the creation and management of the VINTAGE website www.epicentro.iss.it/vintage.

\section{Conflict of interest statement}

There are no potential conflicts of interest or any financial or personal relationships with other people or organizations that could inappropriately bias conduct and findings of this study.

\section{Appendix}

The components of the VINTAGE project Working Group are: Emanuele Scafato (Project Leader), Lucia Galluzzo (Project Coordinator) - Centro Nazionale di Epidemiologia, Sorveglianza e Promozione della Salute, Istituto Superiore di Sanità, Rome, Italy; Peter Anderson, Onno Van Schayck - Faculty of Health, Medicine and Life Sciences, Maastricht University, The Netherlands; Joan Colom, Lidia Segura, Jorge Palacio-Vieira Department of Health, Program on Substance Abuse, Government of Catalonia, Barcelona, Spain; Andrew McNeill - Institute of Alcohol Studies, Huntingdon, United Kingdom; Sandra Radoš Krnel - Research Centre, Institute of Public Health, Ljubljana, Slovenia; Salme Ahlström, Esa Osterberg - National Institute for Health and Welfare, Helsinki, Finland; Hana Sovinova Coordination, Monitoring and Research Unit, National Institute of Public Health, Praha, Czech Republic; Claudia Gandin, Silvia Ghirini, Sonia Martire, Alessandra Rossi, Lucilla Di Pasquale Centro Nazionale di Epidemiologia, Sorveglianza e Promozione della Salute, Istituto Superiore di Sanità, Rome, Italy.

Submitted on invitation.

Accepted on 30 May 2012.

\section{References}

1. Rehm J, Baliunas D, Borges GL, Graham K, Irving H, Kehoe T, et al. The relation between different dimensions of alcohol consumption and burden of disease: an overview. Addiction 2010;105:817-43.

http://dx.doi.org/10.1111/j.1360-0443.2010.02899.x

2. Anderson P, Baumberg B. Alcohol in Europe: a public health perspective. Report to the European Commission. London: Institute of Alcohol Studies; 2006. http://dx.doi.org/10.1 080/09687630600902477.
3. European Union. Council conclusions of 1 December 2009 on alcohol and health (2009/C 302/07). Official Journal of the European Union C302/15, 12.12.2009.

Available from: http://eur-lex.europa.eu/LexUriServLexUriServ. do?uri=OJ:C:2009: 302:0015:0018:EN:PDF.

4. Hallgren MÅ, Högberg P, Andréasson S. Alcohol consumption and harm among elderly Europeans: falling between the cracks. Eur J Public Health 2010;20:616-7. http://dx.doi.org/10.1093/eurpub/ckq111 
5. Scafato E. Alcohol and the elderly: the time to act is now! Eur J Public Health 2010;20:617-8. http://dx.doi.org/10.1093/eurpub/ckq112

6. National Institute on Alcohol Abuse and Alcoholism. Alcohol Alert No. 40: Alcohol and Aging. Bethesda, MD: NIAAA; 1998. Available from: http://pubs.niaaa.nih. gov/publications/ aa40.htm.

7. Oscar-Berman M, Shagrin B, Evert DL, Epstein C. Impairments of brain and behavior: the neurological effects of alcohol. Alcohol Health Res World 1997;21:65-75.

8. Giannakouris K. Ageing characterises the demographic perspectives of the European societies. Eurostat Statistics in Focus 72/2008. Luxembourg: Publications Office of the European Union; 2008. Available from: http://epp.eurostat.ec.europa.eu/cache/ITY_OFFPUB/KS-SF-08-072/EN/ KSSF-08-072-EN.PDF.

9. European Commission. Europe's changing population structure and its impact on relations between the generations. EC Press Releases MEMO/05/96, 17.03.2005. Available from: http://europa.eu/rapid/pressReleasesAction.do?reference=MEMO/05/ $96 \&$ format $=$ HTML\&aged $=0 \&$ language $=\mathrm{EN} \&$ guiLanguage $=$ en.

10. Anderson P, Chisholm D, Fuhr DC. Effectiveness and costeffectiveness of policies and programmes to reduce the harm caused by alcohol. Lancet 2009;373:2234-46. http://dx.doi.org/10.1016/S0140-6736(09)60744-3

11. Anderson P. Evidence for the effectiveness and cost-effectiveness of interventions to reduce alcohol-related harm. Copenhagen: World Health Organization; 2009.

12. Anderson P, Scafato E. Alcohol and older people: a public health perspective. Report for the VINTAGE project; 2010. Available from: http://www.epicentro.iss.it/vintage/ outputs.asp.

13. Ferreira MP, Weems MK. Alcohol consumption by aging adults in the United States: health benefits and detriments. $J$ Am Diet Assoc 2008;108:1668-76. http://dx.doi.org/10.1016/j.jada.2008.07.011

14. Kim SY, Breslow RA, Ahn J, Salem N Jr. Alcohol consumption and fatty acid intakes in the 2001-2002 national health and nutrition examination survey. Alcohol Clin Exp Res 2007; 31:1407-14.

http://dx.doi.org/10.1111/j.1530-0277.2007.00442.x

15. Wilsnack RW, Wilsnack SC, Kristjanson AF, VogeltanzHolm ND, Gmel G. Gender and alcohol consumption: patterns from the multinational GENACIS project. Addiction 2009;104:1487-500.

http://dx.doi.org/10.1111/j.1360-0443.2009.02696.x

16. Hallgren M, Hogberg P, Andreasson S. Alcohol consumption amongst elderly European Union citizens. Stockholm: Swedish National Institute of Public Health; 2009.

17. Hajat S, Haines A, Bulpitt C, Fletcher A. Patterns and determinants of alcohol consumption in people aged 75 years and older: results from the MRC trial of assessment and management of older people in the community. Age Ageing 2004;33:170-7. http://dx.doi.org/10.1093/ageing/afh046

18. Rehm J, Zatonksi W, Taylor B, Anderson P. Epidemiology and alcohol policy in Europe. Addiction 2011;106 (Suppl 1): 11-9.

http://dx.doi.org/10.1111/j.1360-0443.2010.03326.x

19. Jones L, Bellis MA, Dedman D, Sumnall H, Tocque K. Alcohol-attributable fractions for England: alcohol-attributable mortality and hospital admissions. Liverpool: John Moores University, North West Public Health Observatory; 2008. Available from: http://www.nwph.net/nwpho/publications/alcoholattributablefractions.pdf.

20. Rehm J, Patra J, Popova S. Alcohol drinking cessation and its effect on oesophageal and head and neck cancers: a pooled analysis. Int J Cancer 2007;121:1132-7. http://dx.doi.org/10.1111/10.1002/ijc.22798

21. Cawthon PM, Fink HA, Barrett-Connor E, Cauley JA, Dam TT, Lewis CE, et al. Alcohol use, physical performance, and functional limitations in older men. J Am Geriatr Soc 2007;55:212-20. http://dx.doi.org/10.1111/j.1532-5415.2007.01062.x

22. Kirchner JE, Zubritsky C, Cody M, Coakley E, Chen H, Ware $\mathrm{JH}$, et al. Alcohol consumption among older adults in primary care. J Gen Intern Med 2007;22:92-7. http://dx.doi.org/10.1007/s11606-006-0017-z

23. Breeze E, Jones DA, Wilkinson P, Latif AM, Bulpitt CJ, Fletcher AE. Association of quality of life in old age in Britain with socioeconomic position: baseline data from a randomised controlled trial. J Epidemiol Commun H 2004; 58:667-73.

http://dx.doi.org/10.1136/jech.2003.014035

24. Gilbertson R, Ceballos NA, Prather R, Nixon SJ. Effects of acute alcohol consumption in older and younger adults: perceived impairment versus psychomotor performance. $J$ Stud Alcohol Drugs 2009;70:242-52.

25. Tombaugh TN, McIntyre NJ. The mini-mental state examination: a comprehensive review. J Am Geriatr Soc 1992; 40:922-35.

26. Sheik JI, Yesavage JA. Geriatric Depression Scale (GDS): recent evidence and development of a shorter version. Clin Gerontol 1986;37:819-20.

27. Carstairs V, Morris R. Deprivation and health in Scotland. Aberdeen: Aberdeen University Press; 1991.

28. Barnes GM. Alcohol use among older persons: findings from a Western New York State general population survey. J Am Geriatr Soc 1979;27:244-50.

29. Kharicha K, Iliffe S, Harari D, Swift C, Gillmann G, Stuck AE. Health risk appraisal in older people 1: are older people living alone an "at-risk" group? Br J Gen Pract 2007;57:271-6.

30. Peel NM, McClure RJ, Bartlett HP. Behavioral determinants of healthy aging. Am J Prev Med 2005;28:298-304. http://dx.doi.org/10.1016/j.amepre.2004.12.002

31. Wang L, van Belle G, Kukull WB, Larson EB. Predictors of functional change: a longitudinal study of nondemented people aged 65 and older. J Am Geriatr Soc 2002;50:1525-34. http://dx.doi.org/10.1046/j.1532-5415.2002.50408.x

32. Reid MC, Boutros NN, O'Connor PG, Cadariu A, Concato J. The health-related effects of alcohol use in older persons: a systematic review. Subst Abus 2002;23:149-64. http://dx.doi.org/10.1080/08897070209511485

33. Guralnik JM, Kaplan GA. Predictors of healthy aging: prospective evidence from the Alameda County study. Am J Public Health 1989;79:703-8. http://dx.doi.org/10.2105/AJPH.79.6.703

34. Lang I, Guralnik J, Wallace RB, Melzer D. What level of alcohol consumption is hazardous for older people? Functioning and mortality in US and English national cohorts. J Am Geriatr Soc 2007;55:49-57. http://dx.doi.org/10.1111/j.1532-5415.2006.01007.x

35. Papaioannou A, Kennedy CC, Cranney A, Hawker G, Brown JP, Kaiser SM, et al. Risk factors for low BMD in healthy men age 50 years or older: a systematic review. Osteoporos Int 2009;20:507-18. http://dx.doi.org/10.1007/s00198-008-0720-1

36. Nackaerts O, Horner K, Jacobs R, Karayianni K, Mitsea A, Berkas L, et al. Is self-reported alcohol consumption associated with osteoporotic mandibular bone loss in women? Eur J Oral Sci 2009;117:7-12. http://dx.doi.org/10.1111/j.1600-0722.2008.00596.x 
37. Roy DK, O'Neill TW, Finn JD, Lunt M, Silman AJ, Felsenberg D, et al. European Prospective Osteoporosis Study (EPOS). Determinants of incident vertebral fracture in men and women: results from the European Prospective Osteoporosis Study (EPOS). Osteoporos Int 2003;14:19-26. http://dx.doi.org/10.1007/s00198-002-1317-8

38. Cawthon PM, Harrison SL, Barrett-Connor E, Fink HA, Cauley JA, Lewis CE, et al. Alcohol intake and its relationship with bone mineral density, falls, and fracture risk in older men. J Am Geriatr Soc 2006;54:1649-57. http://dx.doi.org/10.1111/j.1532-5415.2006.00912.x

39. Marshall SC. The role of reduced fitness to drive due to medical impairments in explaining crashes involving older drivers. Traffic Inj Prev 2008;9:291-8. http://dx.doi.org/10.1080/15389580801895244

40. Sorock GS, Chen LH, Gonzalgo SR, Baker SP. Alcoholdrinking history and fatal injury in older adults. Alcohol 2006; 40:193-9. http://dx.doi.org/10.1016/j.alcohol.2007.01.002

41. Department for Transport. Reported road casualties Great Britain 2008: Annual Report. UK; UK National Statistics; 2009. Available from: www.dft.gov.uk/pgr/ statistics/datatablespublications/accidents/casualtiesgbar/rrcgb2008.

42. Peters R, Peters J, Warner J, Beckett N, Bulpitt C. Alcohol, dementia and cognitive decline in the elderly: a systematic review. Age Ageing 2008;37:505-12. http://dx.doi.org/10.1093/ageing/afn095

43. Panza F, Capurso C, D'Introno A, Colacicco AM, Frisardi V, Lorusso $\mathrm{M}$, et al. Alcohol drinking, cognitive functions in older age, predementia, and dementia syndromes. $J$ Alzheimers Dis 2009;17:7-31. http://dx.doi.org/10.3233/JAD-2009-1009

44. Weyerer S, Eifflaender-Gorfer S, Köhler L, Jessen F, Maier W, Fuchs A, et al. Prevalence and risk factors for depression in non-demented primary care attenders aged 75 years and older. J Affect Disord 2008;111:153-63. http://dx.doi.org/10.1016/j.jad.2008.02.008

45. Bots S, Tijhuis M, Giampaoli S, Kromhout D, Nissinen A. Lifestyle- and diet-related factors in late-life depression: a 5 -year follow-up of elderly European men: the FINE study. Int J Geriatr Psychiatry 2008;23:478-84. http://dx.doi.org/10.1002/gps.1919

46. Goldberg IJ, Mosca L, Piano MR, Fisher EA, Nutrition Committee, Council on Epidemiology and Prevention, and Council on Cardiovascular Nursing of the American Heart Association. AHA science advisory: Wine and your heart: a science advisory for health care professionals from the Nutrition Committee, Council on Epidemiology and Prevention, and Council on Cardiovascular Nursing of the American Heart Association. Circulation 2001;103:472-5. http://dx.doi.org/10.1161/01.CIR.103.3.472

47. Mukamal KJ, Chung H, Jenny NS, Kuller LH, Longstreth WT Jr, Mittleman MA, et al. Alcohol consumption and risk of coronary heart disease in older adults: The cardiovascular health study. J Am Geriatr Soc 2006;54:30-7. http://dx.doi.org/10.1111/j.1532-5415.2005.00561.x

48. Goldberg RJ, Burchfield CM, Reed DM, Wergowske G, Chiu D. A prospective study of the health effects of alcohol consumption in middle-aged and elderly men. The Honolulu heart program. Circulation 1994;89:651-9. http://dx.doi.org/10.1161/01.CIR.89.2.651

49. Gronbaek M, Deis A, Becker U, Hein HO, Schnohr P, Jensen $\mathrm{G}$, et al. Alcohol and mortality: is there a U-shaped relation in elderly people? Age Ageing 1998;27:739-44. http://dx.doi.org/10.1093/ageing/27.6.739

50. Fillmore KM, Stockwell T, Chikritzhs T, Bostrom A, Kerr W. Moderate alcohol use and reduced mortality risk: sys- tematic error in prospective studies and new hypotheses. Ann Epidemiol 2007;17(Suppl 5):S16-23.

http://dx.doi.org/10.1016/j.annepidem.2007.01.005

51. Abbott RD, Sharp DS, Burchfiel CM, Curb JD, Rodriguez BL, Hakim AA, et al. Cross-sectional and longitudinal changes in total and high-density-lipoprotein cholesterol levels over a 20 -year period in elderly men: the Honolulu Heart Program. Ann Epidemiol 1997;7(6):417-24. http://dx.doi.org/10.1016/S1047-2797(97)00043-4

52. Abrams J, Vela BS, Coultas DB, Samaan SA, Malhotra D, Roche RJ. Coronary risk factors and their modification: lipids, smoking, hypertension, estrogen, and the elderly. Curr Probl Cardiol 1995;20:533-610.

http://dx.doi.org/10.1016/S0146-2806(06)80023-X

53. Abbott RD, Curb JD, Rodriguez BL, Masaki KH, Yano $\mathrm{K}$, Schatz IJ, et al. Age-related changes in risk factor effects on the incidence of coronary heart disease. Ann Epidemiol 2002;12:173-81.

http://dx.doi.org/10.1016/S1047-2797(01)00309-X

54. Lloyd-Jones DM, Martin DO, Larson MG, Levy D. Accuracy of death certificates for coding coronary heart disease as the cause of death. Ann Intern Med 1998;129:1020-6.

55. Mukamal KJ, Kennedy M, Cushman M, Kuller LH, Newman AB, Polak J, et al. Alcohol consumption and lower extremity arterial disease among older adults. Am J Epidemiol 2008;167: 34-41. http://dx.doi.org/10.1093/aje/kwm274

56. Stott DJ, Welsh P, Rumley A, Robertson M, Ford I, Sattar $\mathrm{N}$, et al. Adipocytokines and risk of stroke in older people: a nested case-control study. Int J Epidemiol 2009;38:253-61. http://dx.doi.org/10.1093/ije/dyn215

57. Beulens JW, Stolk RP, van der Schouw YT, Grobbee DE, Hendriks HF, Bots ML. Alcohol consumption and risk of type 2 diabetes among older women. Diabetes Care 2005;28:2933-8. http://dx.doi.org/10.2337/diacare.28.12.2933

58. Djoussé L, Biggs ML, Mukamal KJ, Siscovick DS. Alcohol consumption and type 2 diabetes among older adults: the Cardiovascular Health Study. Obesity 2007;15:1758-65. http://dx.doi.org/10.1038/oby.2007.209

59. Wannamethee SG, Shaper AG, Whincup PH. Modifiable lifestyle factors and the metabolic syndrome in older men: effects of lifestyle changes. J Am Geriatr Soc 2006;54:1909-14. http://dx.doi.org/10.1111/j.1532-5415.2006.00974.x

60. Buja A, Scafato E, Sergi G, Maggi S, Suhad MA, Rausa $\mathrm{G}$, et al. Alcohol consumption and metabolic syndrome in the elderly: results from the Italian Longitudinal Study on Aging. Eur J Clin Nutr 2010;64:297-307. http://dx.doi.org/10.1038/ejen.2009.136

61. Coleman AL, Seitzman RL, Cummings SR, Yu F, Cauley JA, Ensrud KE, et al. The association of smoking and alcohol use with age-related macular degeneration in the oldest old: the study of osteoporotic fractures. Am J Ophthalmol 2010;149:160-9. http://dx.doi.org/10.1016/j.ajo.2009.07.025

62. Baan R, Straif K, Grosse Y, Secretan B, El Ghissassi F, Bouvard $\mathrm{V}$, et al. WHO international agency for research on cancer monograph working group: Carcinogenicity of alcoholic beverages. Lancet Oncol 2007;8:292-3. http://dx.doi.org/10.1016/S1470-2045(07)70099-2

63. Lachenmeier DW, Kantares F, Rehm J. Carcinogenicity of acetaldehyde in alcoholic beverages: risk assessment outside ethanol metabolism. Addiction 2009;104:533-50. http://dx.doi.org/10.1111/j.1360-0443.2009.02516.x

64. Moore AA, Whiteman EJ, Ward KT. Risks of combined alcohol/medication use in older adults. Am $J$ Geriatr Pharmacother 2007;5:64-74. http://dx.doi.org/10.1016/j.amjopharm.2007.03.006 
65. Pringle KE, Ahern FM, Heller DA, Gold CH, Brown TV. Potential for alcohol and prescription drug interactions in older people. J Am Geriatr Soc 2005;53:1930-6. http://dx.doi.org/10.1111/j.1532-5415.2005.00474.x

66. Adams WL. Potential for adverse drug-alcohol interactions among retirement community residents. J Am Geriatr Soc 1995; 43:1021-5.

67. Forster LE, Pollow R, Stoller EP. Alcohol use and potential risk for alcohol-related adverse drug reactions among community-based elderly. J Community Health 1993;18:225-39. http://dx.doi.org/10.1007/BF01324433

68. Onder G, Landi F, Della Vedova C, Atkinson H, Pedone C, Cesari M, et al. GIFA Study. Moderate alcohol consumption and adverse drug reactions among older adults. Pharmacoepidemiol Drug Saf 2002;11:385-92. http://dx.doi.org/10.1002/pds. 721

69. Moore AA, Beck JC, Babor TF, Hays RD, Reuben DB. Beyond alcoholism: identifying older, at-risk drinkers in primary care. J Stud Alcohol 2002;63:316-24.

70. Noale M, Minicuci N, Bardage C, Gindin J, Nikula S, Pluijm $\mathrm{S}$, et al. Predictors of mortality: an international comparison of socio-demographic and health characteristics from six longitudinal studies on aging: the CLESA project. Exp Gerontol 2005;40:89-99.

http://dx.doi.org/10.1016/j.exger.2004.09.003

71. Knoops KT, de Groot LC, Kromhout D, Perrin AE, Moreiras-Varela O, Menotti A, et al. Mediterranean diet, lifestyle factors, and 10-year mortality in elderly European men and women: the HALE project. JAMA 2004;292:1433-9. http://dx.doi.org/10.1001/jama.292.12.1433

72. Babor TF. Alcohol: no ordinary commodity. Research and public policy. $2^{\text {nd }}$ edition. Oxford and London: Oxford University Press; 2010.

http://dx.doi.org/10.1093/acprof:oso/9780199551149.001.0 001

73. Cook PJ. Paying the tab. The costs and benefits of alcohol control. Princeton: Princeton University Press; 2007.

74. Gallet CA. The demand for alcohol: a meta-analysis of elasticities. Aust J Agric Resour Econ 2007;51:121-35. http://dx.doi.org/10.1111/j.1467-8489.2007.00365.x

75. Wagenaar AC, Salois MJ, Komor KA. Effects of beverage alcohol price and tax levels on drinking: a meta-analysis of 1003 estimates from 112 studies. Addiction 2009;104:179-90. http://dx.doi.org/10.1111/j.1360-0443.2008.02438.x

76. Cook PJ, Tauchen G. The effect of liquor taxes on heavy drinking. Bell J Econ 1982;13:379-90. http://dx.doi.org/10.2307/3003461

77. Farrell S, Manning WG, Finch MD. Alcohol dependence and the price of alcoholic beverages. $J$ Health Econ 2003;22:117-47.

http://dx.doi.org/10.1016/S0167-6296(02)00099-1

78. Wagenaar AC, Maldonado-Molina MM, Wagenaar BH. Effects of alcohol tax increases on alcohol-related disease mortality in Alaska: time-series analyses from 1976-2004. Am J Public Health 2009;99:1-8. http://dx.doi.org/10.2105/AJPH.2007.131326

79. Anderson P. Alcohol and the workplace. A report on the impact of work place policies and programmes to reduce the harm done by alcohol to the economy. Report for the FASE project; 2010. Available from: www.faseproject.eu/content/ bestanden/ literature-study-alcohol-and-the-workplace.pdf.

80. O'Connell H, Chin AV, Hamilton F, Cunningham C, Walsh JB, Coakley D, et al. A systematic review of the utility of self-report alcohol screening instruments in the elderly. Int J Geriatr Psychiatry 2004;19:1074-86. http://dx.doi.org/10.1002/gps.1214
81. Berks J, McCormick R. Screening for alcohol misuse in elderly primary care patients: a systematic literature review. Int Psychogeriatr 2008;20:1090-103.

http://dx.doi.org/10.1017/S1041610208007497

82. National Institute for Health and Clinical Excellence. Alcoholuse disorders: preventing the development of hazardous and harmful drinking. NICE Public health guidance 24. London: NICE; 2010. Available from: www.nice.org.uk/nicemedia/ live/13001/48984/48984.pdf.

83. Copeland LA, Blow FC, Barry KL. Health care utilization by older alcohol-using veterans: effects of a brief intervention to reduce at-risk drinking. Health Educ Behav 2003; 30:305-21. http://dx.doi.org/10.1177/1090198103030003006

84. Gordon AJ, Conigliaro J, Maisto SA, McNeil M, Kraemer KL, Kelley ME. Comparison of consumption effects of brief interventions for hazardous drinking elderly. Subst Use Misuse 2003;38:1017-35. http://dx.doi.org/10.1081/JA-120017649

85. Lee HS, Mericle AA, Ayalon L, Areán PA. Harm reduction among at-risk elderly drinkers: a site-specific analysis from the multi-site primary care research in substance abuse and mental health for elderly (PRISM-E) study. Int $J$ Geriatr Psychiatry 2009;24:54-60. http://dx.doi.org/10.1002/gps.2073

86. Harari D, Iliffe S, Kharicha K, Egger M, Gillmann G, von Renteln-Kruse W, et al. Promotion of health in older people: a randomized controlled trial of health risk appraisal in British general practice. Age Ageing 2008;37:565-71. http://dx.doi.org/10.1093/ageing/afn150

87. Zaridze D, Brennan P, Boreham J, Boroda A, Karpov R, Lazarev A, et al. Alcohol and cause-specific mortality in Russia: a retrospective case-control study of 48557 adult deaths. Lancet 2009;373:2201-14. http://dx.doi.org/10.1016/S0140-6736(09)61034-5

88. Anderson P. Time for the middle aged to own up to the problem. Addiction 2009;104:1501-2. http://dx.doi.org/10.1111/j.1360-0443.2009.02728.x

89. Brennan A, Purshouse R, Taylor K, Rafia R, Meier P, Booth A, et al. Independent review of the effects of alcohol pricing and promotion: Part B. Sheffield: University of Sheffield; 2008. Available from: www.dh.gov.uk/en/Publichealth/ Healthimprovement/ Alcoholmisuse/DH_4001740.

90. Rosen M, Haglund B. Trends in alcohol-related mortality in Sweden 1969-2002: an age-period-cohort analysis. Addiction 2006; $101: 835-40$. http://dx.doi.org/10.1111/j.1360-0443.2006.01421.x

91. Taki Y, Kinomura S, Sato K, Goto R, Inoue K, Okada K, et al. Both global gray matter volume and regional gray matter volume negatively correlate with lifetime alcohol intake in non-alcoholdependent Japanese men: a volumetric analysis and a voxelbased morphometry. Alcohol Clin Exp Res 2006;30:1045-50. http://dx.doi.org/10.1111/j.1530-0277.2006.00118.x

92. Collaborative Group on Hormonal Factors in Breast Cancer. Alcohol, tobacco and breast cancer - collaborative reanalysis of individual data from 53 epidemiological studies, including 58 515 women with breast cancer and 95,067 women without the disease. Br J Cancer 2002;87:1234-45. http://dx.doi.org/10.1038/sj.bjc.6600596

93. Rehm J, Room R, Taylor B. Method for moderation: measuring lifetime risk of alcohol-attributable mortality as a basis for drinking guidelines. Int J Methods Psychiatr Res 2008;17:14151.http://dx.doi.org/10.1002/mpr.259

94. Australian Government. Australian guidelines to reduce health risks from drinking alcohol. Canberra: National Health and Medical Research Council; 2009. Available from: www. nhmrc.gov.au/_files_nhmrc/publications/attachments/ds10alcohol.pdf. 